\title{
HIV testing and treatment among adults working in the fishing sector, agricultural estates, and as market vendors in rural southern Malawi
}

Project SOAR

Follow this and additional works at: https://knowledgecommons.popcouncil.org/departments_sbsr-hiv

Part of the Public Health Commons

How does access to this work benefit you? Let us know!

\section{Recommended Citation}

Project SOAR. 2021. "HIV testing and treatment among adults working in the fishing sector, agricultural estates, and as market vendors in rural southern Malawi," Project SOAR Results Brief. Washington, DC: Population Council. 


\section{HIV Testing and Treatment among Adults Working in the Fishing Sector, Agricultural Estates, and As Market Vendors in Rural Southern Malawi}

In line with the UNAIDS 90-90-90 targets $^{1}$ and in collaboration with local implementing partners, the Government of Malawi in its strategic planning has emphasized the reduction of new HIV infections and the impacts of HIV among high-risk populations. In southern Malawi, high-risk populations include those involved in the fishing sector (including fishing, fish processing, and fish trading), in agricultural estate workers, and market vendors. Among these groups, HIV prevalence was $10-22$ percent in $2014 .^{1-3}$

The "One Community" (One-C) program, funded by the United States Agency for International Development (USAID) and implemented by Johns Hopkins Center for Communication Programs (JHU$\mathrm{CCP}$ ), targets these and other high-risk groups for programming to:

- Increase utilization of HIV prevention and care and treatment services.

- Improve linkages to services at the community level.

- Foster the adoption of HIV risk reduction behaviors.

One-C also aims to increase the capacity of community-level organization and service delivery partners to implement high quality HIV prevention and care and treatment services. ${ }^{4}$

This brief focuses on the findings from Project SOAR's monitoring of the One-C project in areas where it is operating in Malawi. The brief describes the characteristics of male and female adults working in the fishing sector, in agricultural estates, and as market vendors. It also describes the prevalence of HIV testing and treatment among these populations and explores whether participation in One-C activities is associated with higher uptake of HIV services.

\section{KEY FINDINGS}

- Women working in the fishing sector, in agricultural estates, and as market vendors were less educated, more likely to be divorced or widowed, more likely to be poor, and more likely to report a positive HIV status than their male counterparts.

- While the data show progress in achieving 90-90-90 indicators in other ways, adherence to ARV medication reveals a downward trend over time with a reduction of nearly 20 percent over two years for both men and women.

- Men were more likely to participate in the One Community meetings than were women, suggesting One Community was effective in reaching men, who are usually more difficult to engage in HIV programming than women.

- Participation in One Community group meetings was associated with HIV testing among non-HIV-positive respondents, but it was not associated with HIV treatment among HIV-positive respondents.

\section{METHODS}

Population Council, under Project SOAR, conducted three rounds of cross-sectional household interviews in 2017, 2018, and 2019 in 24 health facility catchment areas in five districts of southern Malawi-Blantyre, Chikwawa, Mangochi, Mulanje, and Phalombe-where the One-C program was to be scaled. An exhaustive household census was conducted to identify households with the priority

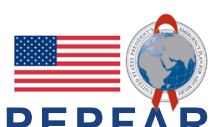

PEPFAR 
populations, and a random sample of households with adult members who had temporarily or permanently worked in the past 12 months in the fishing sector, in agricultural estates, or as market vendors were selected to be interviewed. In each round, samples were redrawn to achieve crosssectional representation of the target populations.

Self-reported data were collected on sociodemographic characteristics, HIV testing and treatment, and participation in One-C project group meetings. Logistic regressions were used to assess differences by sex and across survey rounds. Logistic regressions were also used to assess associations with participation in One-C group meetings, while controlling for survey round, district, and respondent's sex, age, grade attainment, literacy, religion, marital status, and household wealth. Regressions were estimated with robust standard errors to account for clustering at the census enumeration areas (CEA) level. As the data are cross-sectional and are not embedded within a rigorous evaluation design, the associations between program participation and outcomes need be interpreted with caution.

\section{MEASURES}

\section{Participation in One-C group meetings}

Participation in One-C group meetings was measured as a binary variable that indicated whether the respondent had participated in at least one of the following two components that were part of the One-C project: (1) care group meetings and (2) HIV assessment and risk reduction meetings. The latter component was targeted toward people working in the fishing sector, market vendors, or estate workers, whereas these groups were not targeted for the care group meetings. However, in some cases, respondents were exposed to care group meetings, because they were part of a household that was targeted by One-C for other reasons.

\section{HIV testing}

The study included two measures of HIV testing among non-HIV-positive respondents:
- Ever tested for HIV

- Tested for HIV and received results within the past six months

\section{HIV treatment}

The study included three self-reported measures of HIV treatment among those self-reporting to be HIVpositive:

- Currently taking any antiretroviral (ARV) medication

- Adherence to ARV medication, defined as never having missed or forgotten to take their ARV medication in the past six months

- Tested for viral load in the past six months

\section{RESULTS}

\section{Who are the adults working in the fishing sector, in agricultural estates, and as market vendors?}

Table 1 presents descriptive statistics for select sociodemographic characteristics of the pooled samples by sex. Overall, 45 percent of respondents were men and 55 percent were women. Adjusting for differences across rounds, on average, women were younger, had lower grade attainment, and were less likely to be literate than men. Women were less likely to be currently married/cohabiting and never married than men, but they were more likely to have been previously married than men. Women lived in households that were more likely to be poor than the households in which the men lived.

\section{Men were almost four times as likely than women to have never been tested for HIV, and among those respondents who tested, 14 percent of women and about 8 percent of men reported testing HIV-positive.}

Table 2 presents the self-reported HIV status among the pooled samples by sex. Men were almost four times as likely than women to have never been tested for HIV. Among those who had obtained 
Table 1 Select sociodemographic characteristics by sex, pooled samples 2017-2019

\begin{tabular}{|c|c|c|}
\hline & $\begin{array}{c}\text { Men } \\
n=1,117 \\
\%\end{array}$ & $\begin{array}{c}\text { Women } \\
n=1,364 \\
\%\end{array}$ \\
\hline Age, mean (sd) & $36.4(12.2)$ & $34.9(12.2)$ * \\
\hline Grade, mean (sd) & $5.3(3.5)$ & $4.5(3.5)$ * \\
\hline Literate & 73.1 & $57.3 *$ \\
\hline \multicolumn{3}{|l|}{ Religion } \\
\hline Christian & 66.0 & 66.2 \\
\hline Muslim & 34.2 & 33.8 \\
\hline \multicolumn{3}{|l|}{ Marital status } \\
\hline $\begin{array}{l}\text { Married/living } \\
\text { together }\end{array}$ & 91.6 & $67.5 *$ \\
\hline $\begin{array}{l}\text { Divorced/ } \\
\text { separated }\end{array}$ & 2.6 & $21.3 *$ \\
\hline Widowed & 0.5 & $8.9 *$ \\
\hline Never married & 5.3 & $2.3^{*}$ \\
\hline \multicolumn{3}{|l|}{ Household wealth } \\
\hline Lowest & 9.4 & $21.3 *$ \\
\hline Middle & 61.3 & 59.5 \\
\hline Highest & 29.3 & $19.2^{*}$ \\
\hline
\end{tabular}

Household wealth was measured using principal components analysis (PCA) on 15 variables: having electricity, solar panel, radio, television, refrigerator, bed with mattress, table and chairs, watch, mobile phone, bicycle, motorcycle/scooter, car/other vehicle, dwelling floor material, total farm animals owned, and household savings. The PCA was performed on the round one sample and wealth quintiles were generated. Three categories were constructed: the poorest (based on the lowest baseline quintile cutoff), the middle (reference category), and the richest (based on the highest baseline quintile cutoff). The scoring factors from the PCA and the round one wealth quintile cutoffs were then applied to the data from rounds 2 and 3.

$* p<0.05$ for differences by sex, adjusting for survey round and clusters in CEAs.

an HIV test result, only two men across the three survey rounds refused to disclose their HIV status, and women were almost twice as likely than men to self-report being HIV-positive. The self-reported prevalence of HIV seems low for these populations, as recent estimates of HIV prevalence in this region among persons aged 15-64 are between 12-13 percent for men and 17-18 percent for women. ${ }^{4}$
Table 2 Respondents' self-reported HIV testing and status by sex, pooled samples 2017-2019

\begin{tabular}{|c|c|c|}
\hline & $\begin{array}{c}\text { Men } \\
n=1,117 \\
\%\end{array}$ & $\begin{array}{c}\text { Women } \\
\mathrm{n}=1,364 \\
\%\end{array}$ \\
\hline Never been tested for HIV & 9.2 & $2.4^{*}$ \\
\hline $\begin{array}{l}\text { Ever tested for HIV but did not } \\
\text { obtain result during the last } \\
\text { time tested }\end{array}$ & 0.7 & 0.7 \\
\hline $\begin{array}{l}\text { Ever tested for HIV and } \\
\text { obtained result during the last } \\
\text { time tested }\end{array}$ & 90.1 & $97.0 *$ \\
\hline If obtained HIV test result & $n=1,006$ & $n=1,323$ \\
\hline Refused to disclose result & 0.2 & 0.0 \\
\hline HIV-positive & 7.7 & $14.0 *$ \\
\hline HIV-negative & 92.0 & $85.9 *$ \\
\hline Indeterminate & 0.2 & 0.1 \\
\hline
\end{tabular}

* $p<0.05$ for differences by sex, adjusting for survey round and clusters in CEAs.

\section{The percent of respondents who reported ever testing for HIV was high, and slightly higher for women than men.}

Figure 1 Percent of respondents who reported ever testing for HIV, 2017-2019

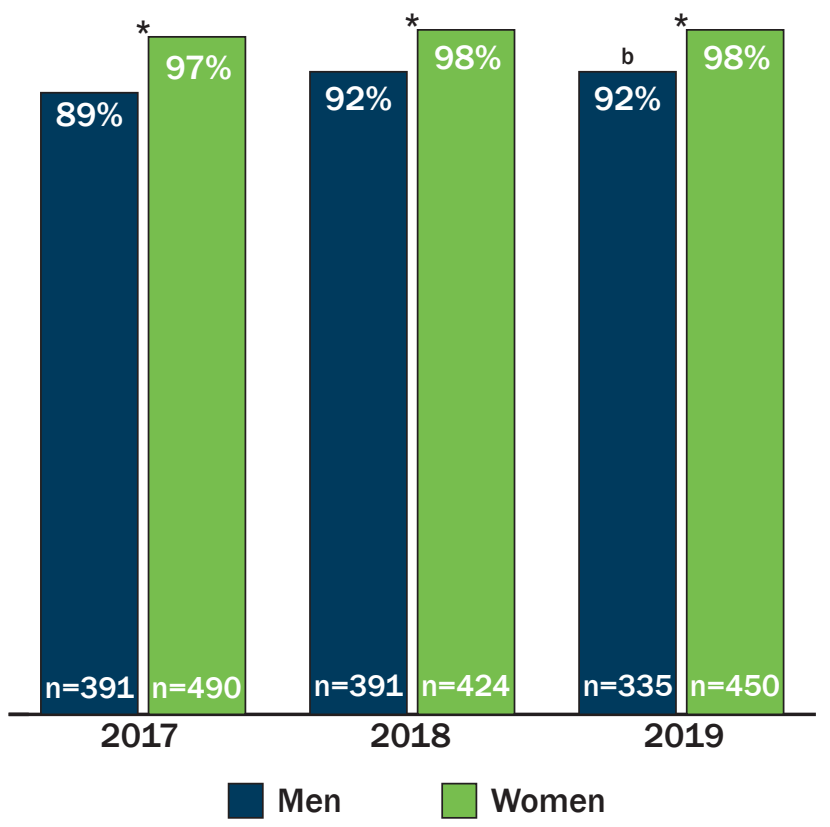

${ }^{*} p<0.05$ for differences by sex, adjusting for clusters in CEAs.

${ }^{\mathrm{b}} \mathrm{p}<0.1$ for differences relative to 2017 , adjusting for clusters in CEAs. 
Increases across time in the percentage of respondents obtaining an HIV test result were observed for both men and women.

Overall, non-HIV-positive women were more likely to have obtained an HIV test result within the past six months than their male peers (Figure 2).

\section{Figure 2 Percent of non-HIV-positive respondents who were tested for HIV and received their result within the past 6 months, 2017- 2019}

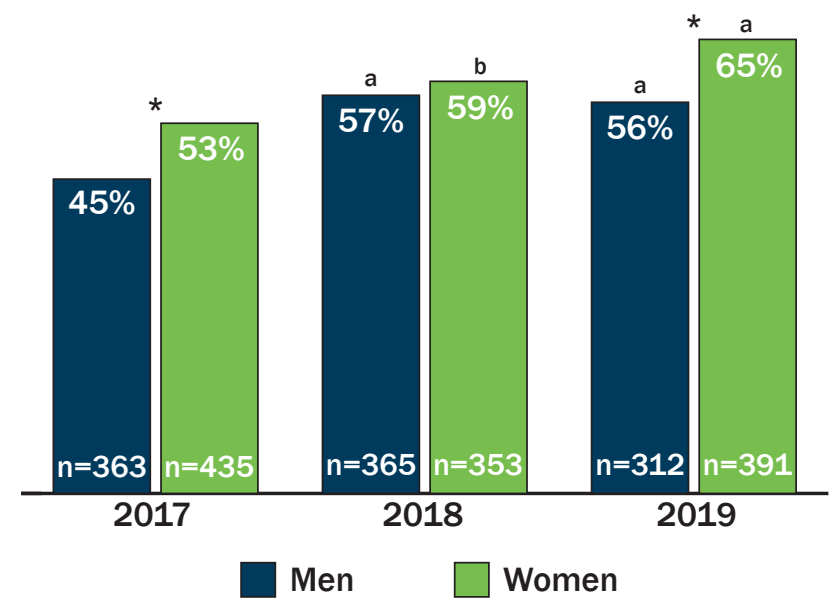

$* p<0.05$ for differences by sex, adjusting for clusters in CEAs.

${ }^{a} p<0.05,{ }^{b} p<0.1$ for differences relative to 2017 , adjusting for clusters in CEAs.

\section{The percent of HIV-positive respondents reporting taking ARV medication was high and increased over time.}

The predominant majority of self-reported HIVpositive respondents were taking ARV medication (Figure 3). Women were more likely to be on ARVs than men and increases were observed for both relative to 2017 , although none of the differences is statistically significant. These figures are noticeable, as estimates of treatment among persons aware of their HIV-positive status are around 70 percent for this region. ${ }^{5}$
Figure 3 Percent of HIV-positive respondents who were taking ARV medication, 2017-2019

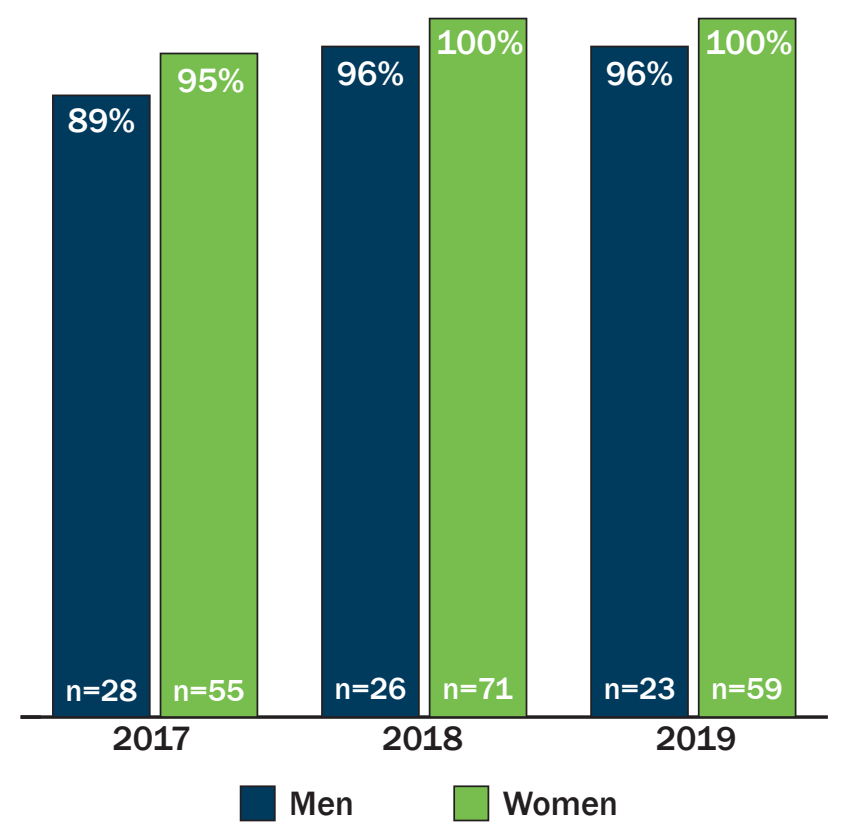

As can be observed in Figure 4, there are no statistically significant or meaningful differences between men and women in adherence to ARV medication among those reported being positive. However, there is a noticeable negative trend in adherence over time, becoming statistically significantly lower among women by 2019. As adherence is related to viral suppression, this finding stands out relative to the key 90-90-90 indicators.

A higher percentage of HIV-positive women than men were tested for viral load within the past six months, but the difference was only marginally statistically significant in 2018 (Figure 5). Increases are observed in 2018 and sustained in 2019 for women, while for men only 2019 shows higher testing for viral load; however, none of these differences is statistically significant. 
Figure 4 Percent of HIV-positive respondents taking ARV medication who have adhered in the past 6 months, 2017-2019

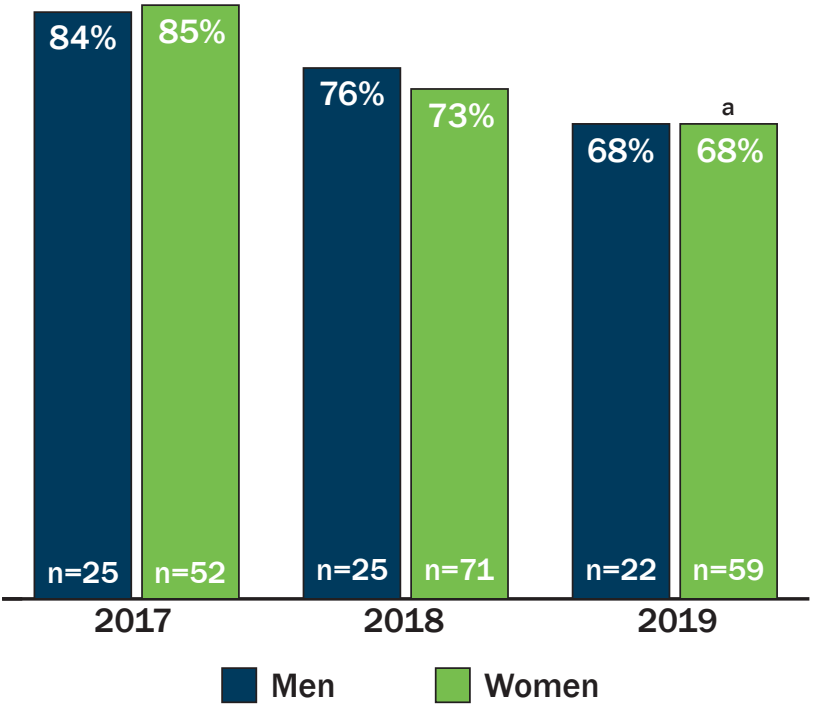

${ }^{a} p<0.05$ for differences relative to 2017 , adjusting for clusters in CEAs.

Figure 5 Percent of HIV-positive respondents who were tested for viral load in the past 6

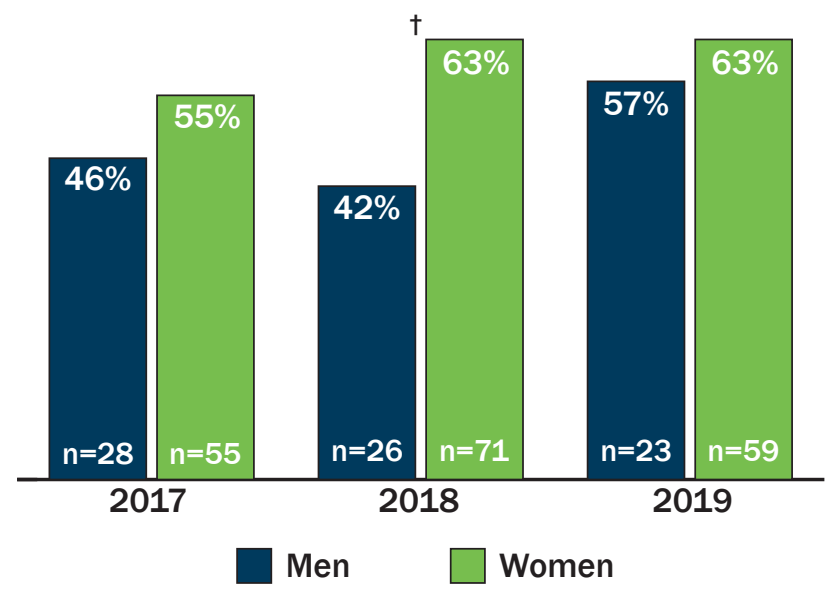

months, 2017-2019

${ }^{\dagger} p<0.1$ for differences by sex, adjusting for clusters in CEAs.
Men were more likely to have heard of the One-C program than women and more likely to have participated in the One-C meetings than women.

Among the polled respondents interviewed in 2018 and 2019, men were more likely to have heard of the One-C project than women and more likely to have participated in the One-C meetings than women (Table 3).

Table 3 Respondents' self-reported exposure to and participation in One-C group meetings by sex, pooled samples, 2018-2019

\begin{tabular}{lcc|} 
& $\begin{array}{c}\text { Men } \\
n=726\end{array}$ & $\begin{array}{c}\text { Women } \\
n=874\end{array}$ \\
$\begin{array}{l}\text { Heard of One-C } \\
\text { Participated in HIV care }\end{array}$ & 52.2 & $39.5^{*}$ \\
$\begin{array}{l}\text { group meetings } \\
\text { Participated in HIV } \\
\text { assessment and risk } \\
\text { reduction meetings }\end{array}$ & 3.2 & 2.9 \\
$\begin{array}{l}\text { Participated in any } \\
\text { meeting }\end{array}$ & 12.7 & $7.6^{*}$ \\
\hline
\end{tabular}

$* p<0.05$ for differences by sex, adjusting for survey round and clusters in CEAs.

\section{Participation in One-C meetings was associated with higher odds of HIV testing in the past six months for both men and women.}

Table 4 presents odds ratios and confidence intervals for participation in One-C meetings from pooled logistic regressions for the 2018 and 2019 survey rounds. Participation in One-C meetings is statistically significantly associated with higher odds of having obtained an HIV test result in the past six months for both men and women (men OR 2.1, Cl 1.44-3.04; women OR 1.6, Cl 1.04-2.48). Adherence to ARV medication and testing for viral load in the past six months were not statistically significantly associated with One-C group meeting participation among respondents who reported testing positive for HIV. 
Table 4 Results from pooled logistic regressions for HIV testing and treatment indicators in the past 6 months, OR, and $95 \% \mathrm{Cl}$ for selfreported participation in One-C group meetings, 2018-2019

\begin{tabular}{|c|c|c|c|}
\hline \multirow{2}{*}{$\begin{array}{l}\text { HIV testing and } \\
\text { treatment outcomes }\end{array}$} & \multirow[b]{2}{*}{ Sample } & \multicolumn{2}{|c|}{$\begin{array}{l}\text { Participated in One-C } \\
\text { group meetings }\end{array}$} \\
\hline & & OR & $95 \% \mathrm{Cl}$ \\
\hline \multicolumn{4}{|l|}{ Full sample } \\
\hline Ever tested for HIV & 1,600 & $2.40 *$ & $(1.14-5.03)$ \\
\hline Men & 726 & 2.14 & $(0.99-4.62)$ \\
\hline Women & 874 & $N / A^{a}$ & \\
\hline \multicolumn{4}{|l|}{$\begin{array}{l}\text { Non-HIV-positive } \\
\text { sample }\end{array}$} \\
\hline $\begin{array}{l}\text { Obtained HIV test } \\
\text { result in past } 6 \\
\text { months }\end{array}$ & 1,421 & $1.86^{*}$ & $(1.39-2.49)$ \\
\hline Men & 677 & $2.10 *$ & $(1.44-3.04)$ \\
\hline Women & 744 & $1.60 *$ & $(1.04-2.48)$ \\
\hline \multicolumn{4}{|l|}{ HIV-positive sample } \\
\hline $\begin{array}{l}\text { Adherent to ARV } \\
\text { medication in past } \\
6 \text { months }\end{array}$ & 177 & 1.05 & $(0.51-2.17)$ \\
\hline $\begin{array}{l}\text { Tested for viral load } \\
\text { in past } 6 \text { months }\end{array}$ & 179 & 0.93 & $(0.43-2.03)$ \\
\hline
\end{tabular}

All regressions control for survey round, district, and respondent's sex, age, grade attainment, literacy, religion, marital status, and household wealth. Robust standard errors adjusted for clusters in CEAs.

${ }^{*} \mathrm{p}<0.05$, ${ }^{\mathrm{a}} \mathrm{All}$ women who participated in One-C group meetings had ever been tested.

\section{CONCLUSIONS AND RECOMMENDATIONS}

Women working in the fishing sector, in agricultural estates, and as market vendors faced more vulnerabilities than their male peers: women had lower schooling attainment and were less likely to be literate, more likely to be divorced or widowed, and more likely to live in the poorest households than men. Further, women faced a higher risk of HIV. Despite these differences, men were more likely than women to have participated in the One-C meetings.
While trends in the key 90-90-90 indicators are promising regarding HIV testing rates and ever taking ARV medication, there are indications that the trends for adherence to ARV medications are concerning.

This study found that participation in the One-C meetings was associated with both ever HIV testing among all respondents and HIV testing within the previous six months among non-HIV positive respondents. Participation in the One-C meetings, however, was not associated with improvements in HIV treatment among the self-reported HIV-positive respondents. While access to HIV treatment is high among this population, with 96 percent of men and 100 percent of women taking ARVs in 2018 and 2019 , adherence is a concern, as it appears to have declined across time. Further, fewer than two-thirds of respondents with HIV were tested for their viral load within the past six months. These findings suggest that work remains to be done for the 90-9090 targets to be achieved.

\section{REFERENCES}

1. UNAIDS. 2017. "90-90-90 An ambitious treatment target to help end the AIDS epidemic." Geneva, Switzerland.

2. Government of Malawi. 2015. "Malawi AIDS Response progress report 2015." Lilongwe, Malawi: Government of Malawi.

3. National Statistical Office (NSO) and ICF Macro. 2011. Malawi Demographic and Health Survey 2010. Zomba, Malawi, and Calverton, Maryland, USA: NSO and ICF Macro.

4. One Community. https://ccp.jhu.edu/projects/one-community/

5. Ministry of Health, Malawi. 2018. "Malawi Population-Based HIV Impact Assessment (MPHIA) 2015-2016: Final report.” Lilongwe: Ministry of Health

\section{ACKNOWLEDGMENTS}

We would like to thank the participants of this study and Ephraim Wadonda Chirwa, Peter Mvula, and our fieldwork teams at Wadonda Consult Limited. We dedicate this work to Ephraim Wadonda Chirwa, who passed away after the conclusion of this study in 2019.

Suggested citation: Project SOAR. 2021. "HIV testing and treatment among adults working in the fishing sector, agricultural estates, and as market vendors in rural southern Malawi," Project SOAR Results Brief. Washington, DC: Population Council.
Project SOAR is a six-year+ (September 2014-January 2021) cooperative agreement funded by the U. S. President's Emergency Plan for AIDS Relief (PEPFAR) and the U. S. Agency for International Development (Agreement No. AID-OAA-A-14-00060). The contents of this brief are the sole responsibility of Project SOAR and Population Council and do not necessarily reflect the views of PEPFAR, USAID, or the United States Government.

Population Council leads the Project SOAR consortium in collaboration with Avenir Health, Elizabeth Glaser Pediatric AIDS Foundation, the Johns Hopkins University, Palladium, and The University of North Carolina at Chapel Hill.
Project SOAR/Population Council 4301 Connecticut Avenue, NW, Suite 280 Washington, DC 20008

Tel: +12022379400

e-mail: ProjectSOAR@popcouncil.org projsoar.org

(C)Population Council, January 2021 